\title{
The Application of Meta-Analytic SEM on Exploring Factors that Influence Teachers' Usage of Interactive Whiteboard
}

\author{
Yi-Horng Lai ${ }^{1 *}$ \\ ${ }^{1}$ Department of Healthcare Administration, Oriental Institute of Technology, New Taipei City, TAIWAN
}

*Corresponding Author: f1006@mail.oit.edu.tw

Citation: Lai, Y.-O. (2019). The Application of Meta-Analytic SEM on Exploring Factors that Influence Teachers' Usage of Interactive Whiteboard. Pedagogical Research, 4(3), em0038. https://doi.org/10.29333/pr/5854

Published: July 22, 2019

\begin{abstract}
Background: Interactive whiteboard (IWB) is an important tool in computer-assisted instruction (CAI). Interactive whiteboard is an electronic instructional and interactive technology designed by use for teachers. Some studies declare that teachers' behaviors in using interactive whiteboard only be infected by perceived usefulness, for teachers are a relatively profession. Material and methods: This paper integrated the 27 studies that used technology acceptance model (TAM) with meta-analytic structural equation modelling (Meta-Analytic SEM). Results: The estimate of perceived usefulness (PU) to Perceived ease of use (PEOU) is 0.585 (p-value $<0.001$ ). The estimate of PU to attitude (ATT) is 0.693 (p-value $<0.001$ ). The estimate of PU to behavioral intentions (BI) is 0.573 ( $\mathrm{p}$-value $<0.001$ ). The estimate of PEOU to ATT is 0.663 ( $\mathrm{p}$ value $<0.001$ ). The estimate of PEOU to $\mathrm{BI}$ is 0.549 ( $\mathrm{p}$-value $<0.001$ ). The estimate of ATT to BI is 0.663 ( $\mathrm{p}$-value $<0.001$ ). Conclusions: PEOU has a positive effect on PU and ATT toward using interactive whiteboard. PU has a positive effect on attitude toward using interactive whiteboard and BI to use interactive whiteboard. Attitude toward using interactive whiteboard has a positive effect on and BI to use interactive whiteboard.
\end{abstract}

Keywords: Interactive whiteboard (IWB), computer-assisted instruction (CAI), technology acceptance model (TAM), meta-analytic structural equation modelling (Meta-Analytic SEM)

\section{INTRODUCTION}

Information technology is rapidly changing the way people live and work, and the field of teaching is no exception. Educational institutions have tried to provide students better learning environments by equipping them with the latest technology. This effort has encouraged instructors to use various assistive technologies such as multimedia and the Internet in their classrooms especially over the last decade, and this integration process of information technologies and education is called computer-assisted instruction (CAI) (Hsu, 2010). As a part of the integration process, the interactive whiteboard (IWB) is one of the important topics of CAI (Holmes, 2009). An interactive whiteboard (IWB) is defined as a touch-sensitive board, linked to a computer and a digital projector. The computer can be commanded by touching the board, directly also with a particular pen. The projector can then show images from the computer on the board (Zhang, 2019). Interactive whiteboards had the potential to be identified with new digital classrooms just as blackboard played a key role in traditional classrooms. Interactive whiteboards can have many positive effects on teaching and learning in general. For teachers, during regular class hours, they provide the opportunity to integrate more information technologies into lessons, enable teachers to utilize a wide range of web-based resources, and encourage them to save and print their notes that they make during lessons. Singaravelu (Singaravelu, 2017) indicated that teaching with interactive whiteboard is more 
convenient for teachers and students compared with teaching by a traditional board. According to Gashan and Alshumaimeri (2015), although some teachers pointed out that they lacked sufficient training in using interactive whiteboards, most of them agreed positively that the interactive whiteboard does not scare them and makes teaching more comfortable. The most importantly, online tools and digital devices in schools have led to educators' increased use of interactive whiteboards in teaching and learning. Teachers must use technology efficiently and bring new pedagogies to their instruction.In many countries, huge amounts of declared funding has been assigned to education sectors for promoting interactive whiteboards in classes, particularly in the elementary school and high school (Taylor and Todd, 1995). Associated studies have proven that interactive whiteboards with the interactive features will attract students' attention and increase concentration. Some studies (Olivares and Castillo, 2018) indicated that interactive whiteboards strengthen students' motivation in learning. The teachers' attitudes and technological skills effects motivation significantly (Tosuntaşa, Karadağa, and Orhanb, 2015). When teachers understanding that interactive whiteboard technology is easy to use and could improve the quality of teaching in classrooms, teachers will use interactive whiteboard in their classes. Emerging evidence implies that teachers' preparation and students' attitudes influence the virtue of technology-enabled learning surroundings. DiGregorio, and Sobel-Lojeski indicated that pedagogy, technical, attitude and curriculum issues are main concerns for developing advisers' CAI teaching skills (DiGregorio and Sobel-Lojeski, 2010). In recent years, the interactive whiteboard is a relatively new CAI tool introduced into classrooms. Researchers had found that many benefits of using them to develop into enhancing students learning experiences in the future (Olivares, Castillo, 2018). Wong, Teo, and Russo (2013) further indicates that providing proper training is the best significant way to help teachers to successfully use interactive whiteboards in their classrooms. In the beginning, training is usually offered by enterprises or interactive whiteboard suppliers, which is not enough for most beginner adopters (Wong, Teo, and Russo, 2013). That means additional formal training conferences and informal learning courses should be organized to make sure that teachers realize how to effectively use interactive whiteboards. With the theory of reasoned actions (TRA), technology acceptance model (TAM) addresses factors influencing a user's attitude toward using and their intention to use technology (Davis, Bagozzi, and Warshaw, 1989). TAM has been widely adopted in studies exploring technology acceptance due to its parsimonious nature and highly reliable constructs. Examples include studies testing user acceptance of mobile devices in learning (Al-Emran, Mezhuyev, and Kamaludin, 2018), e-learning (Abdullah and Ward, 2016), NXT robot in learning (Shin, Shih, Li, Chen, Chen, and Chen, 2011), and interactive whiteboard (Wong, Teo, and Russo, 2013).TAM considers perceived usefulness (PU) and perceived ease of use (PEOU) as two major factors influencing a user's behavioral intention (BI) in using new technology (Šumaka and Šorgoab, 2016). The former refers to the perceived effectiveness of improving the user's performance, while the latter refers to how effortless a user perceives using the technology to be. Prior research has found that PEOU mostly influences attitude and intention indirectly through PU (Wong, Teo, and Russo, 2013). Perceived usefulness and user attitude in turn influence intention to use, which predicts actual usage of technology. Based on TAM model (Davis, Bagozzi, and Warshaw, 1989), PEOU and PU positively affect users' attitude in using interactive whiteboard; and PEOU positively affect users' ATT. The result of Huang (Kuo, 2017), Chiang (2017), Hsueh (2013), and Li (2012)'s study is consistent with the TAM model. However, some studies (Kung, 2010; Ou, 2010) indicated that PEOU does mot positively affect users' attitude toward using (ATT) in the usage of interactive whiteboard. They claimed that the usefulness of technology plays a more important role than the ease of use in affecting teachers' decisions to use new information technology, because teachers are capable of learning new technology quickly and thus perceived ease of use is not very important.The combining of SEM and meta-analysis improves the estimation of structural equation models. SEM requires large sample sizes while combining the information from many samples and studies. Studies without the integration of these two methods can only give partial solution to the research questions. Integration of SEM and meta-analysis can acquire a more complete set of hypotheses and estimated parameters (Cheung, 2015; Jak, 2015).The main objective of this study is to integrate existing research that used theory-based TAM models through the general framework of metaanalytic structural equation modelling (meta-analytic SEM). This integration enables a more accurate interpretation of modeling results in a broader context of data and a comparison of the findings based on primary data.

\section{MATERIALS AND RESEARCH METHOD}

In Davis, Bagozzi, and Warshaw's study (1989), behavioral intentions to use (BI), attitude toward use (ATT), perceived usefulness (PU), and perceived ease of use (PEOU) are integrated. Figure 1 shows the research framework of this present study in a TAM model. From this figure, we can find that 1) PEOU, and PU positively affect users' attitude in using interactive whiteboard (H2, and H3). 2) PEOU positively affects users' AT'T (H1). 3) PU and ATT positively affects users' behavioral intentions to use interactive whiteboard ( $\mathrm{H} 4$, and $\mathrm{H} 5$ ). 


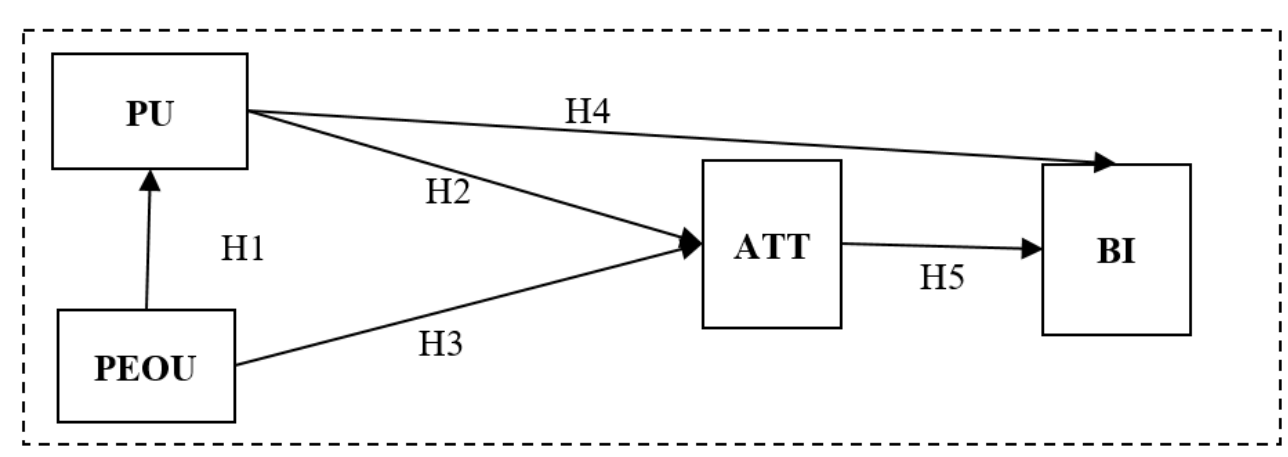

Technology Acceptance Model

Figure 1. Research framework in this study (Davis, Bagozzi, and Warshaw, 1989)

Table 1. The research data in this study

Author Title

M. H. Kuo (2017) Study on the Satisfaction of Kindergarten Teachers with Interactive Whiteboard Teaching

T. Y. Chiang (2017) Preschool Teacher's Acceptance of Interactive Whiteboards(IWB):A Study Based on the Technology Acceptance Model

C. P. Hsueh (2013) Applying the Technology Acceptance Model to Explore the Elementary School Teachers' Present Situation and Usage Intentions of Using Interactive Whiteboard in Tainan City

H. C. Li (2012) The Investigation of Elementary School Teachers' Intentionsand Present Situation of Using Interactive Whiteboard in Tainan City

C. L. Kung (2010) A Study of Adoption Intention of Using Interactive Whiteboard of Primary School Teachers in Kaohsiung County: Apply the Technology Acceptance Model

W. C. Ou (2010) To Explore the Adoption of Electronic White Board in Elementary Schools Using The Technology Acceptance Model

C. H., Hsieh (2015) A Study of Kindergarten Teachers' Acceptance of the Use of Interactive Whiteboards

P. Y. Chou (2015) The Intention of Elementary School Teachers of Integrating Information Technology into Teaching through Extended Technology Acceptance Model-A Case Study of Interactive White Board

M. R. Wu (2014) The Study of Using the Technology Acceptance Model to Examine Elementary School Teachers' Integrating IWB into Teaching

Y. H. Zeng (2014) The Investigation of Acceptance and Current Situation of Using Interactive Whiteboard in Tainan City Elementary School Special Education Teachers

J. H. Hsiao (2013) Using Technology Acceptance Model to Explore the Adoption of Interactive Whiteboard of Elementary Schools Teachers in National Taipei University of Education Experimental Elementary School

J. R. You (2013) A Study of Primary and Junior High School Teachers' Continued Use Intention of Interactive Whiteboard in Taitung and Huailan-based on Technology Acceptance Model and Expectation Confirmation Theory,

L. S. Chen (2013) A Study of Key Factors Associated with Behavioral Intention in Using Interactive Whiteboard by the Elementary School Teachers in Taipei

K. S. Huang (2012) A Survey of Teaching Situation of Elementary School Teachers on Using White Board in Pingtung County

W. T. Chu (2012) A Study of elementary school teachers' in using Interactive Whiteboard teaching from the aspect of Technology Acceptance Model (TAM) for the expectations benefits

C. C. Lin (2012) The Study on Using the Technology Acceptance Model for the Behavioral Intention of Interactive Whiteboard by the Resource Classrooms of Elementary Schools in Changhua County

F. Y. Yang (2012) A Study on the IWB Teaching Attitude \&; Behavior by Elementary School Teachers-using the Technology Acceptance Model C. Y. Sue (2012) Study on Technology Acceptance of Elementary School Teachers Using Interactive White Board

L. B. Chen (2011) A Study on the Factors Affecting Elementary School Teachers'Use of Whiteboard

C. Y. Peng (2011) The teacher's acceptance on an interactive White Board in a kindergarten course - the TAM perspective

C. C. Shen (2011) A Study on The Value Cognitive Structure of Interactive Information Technology - Based on The Case of Interactive White Board

S. Y. Lee (2011) The Behavioral Intention of Elementary Teachers Using Interactive White Board Study

C. H. Lin (2011) The Critical Factors Affecting Elementary and Junior High School Teachers' Use of Interactive Whiteboard

C. C. Huang (2010) A Discussion of the Utilization for Interactive White Board in Information Technology Integrated Instruction by Junior High School Teachers

C. Y. Weng (2010) The Study of the Acceptance of the Incorporation of Interactive White Board as an Innovativeness and Technology Acceptance Mode by Elementary School Teachers in Yunlin County

C. C. Wang (2010) The Study of the Acceptance of the Incorporation of Interactive White Board as an Innovativeness and Technology Acceptance Mode by Elementary School Teachers in Yunlin County

S. C. Ro (2010) The Study of Using Technology Acceptance Model to Explore the Adoption of Interactive Whiteboard of Elementary Schools Teachers in Taoyuan County

\section{Data Source}

For enough information (such as covariance matrix, observed variables, and questionnaires) for Meta-Analytic SEM, this study only focus on master thesis and doctoral thesis. This present paper selected 27 studies that published after 2010 from Taiwan Theses and Dissertations Knowledge Value-Added System (Taiwanese National Central Library, 2010) to do meta-analysis. All these 27 studies explored Taiwanese teachers' behaviors in using interactive whiteboard is as shown in Table 1. 
Table 2. Estimated pooled correlation coefficients (fix-effect parameters)

\begin{tabular}{ccccc}
\hline & Estimate & S.E. & z-value & P(>[z] $)$ \\
\hline PU-PEOU & 0.585 & 0.023 & 25.459 & $<0.001$ \\
\hline PU-ATT & 0.693 & 0.018 & 38.005 & $<0.001$ \\
\hline PU-BI & 0.573 & 0.023 & 24.316 & $<0.001$ \\
\hline PEOU-ATT & 0.663 & 0.019 & 33.843 & $<0.001$ \\
\hline PEOU-BI & 0.549 & 0.024 & 22.454 & $<0.001$ \\
\hline ATT-BI & 0.663 & 0.019 & 33.846 & $<0.001$ \\
\hline
\end{tabular}

\section{Meta-analytic SEM}

Meta-analytic SEM is an extension of the classical individual structural equation modeling. It aims to solve the important scientific problem of integrating, combining and comparing research findings. The meta-analysis is a statistical analysis of a large collection of analysis results from individual studies for the purpose of integrating the findings (Glass, 1976). It can generalize findings across studies, identify potential moderators in the model structure and obtain the appropriate estimates given a larger sample sizes. Structural equation modeling is a powerful statistical method for estimating multivariate regression models with latent variables that combines regression analysis with confirmatory factor analysis.

Meta-analytic structural equation modeling usually is applied as a two-stage approach. In stage 1, the homogeneity of correlation matrices is tested and pooled correlation matrix is estimated. In stage 2, SEM models based on pooled correlation matrix are estimated. Estimation of pooled correlation coefficients in univariate approach is given as a weighed correlations or weighed Fisher-z scores.

The univariate approach is not broadly recommended because not all studies include all variables, and this problem will cause lack of precision in the estimation. In the multivariate approach, the generalized least squares (GLS) or two-stage structural equation modeling that is based on all correlation coefficients and their dependence is used. In meta-analytic structural equation modeling, the two-stage approach gains more popularity because it uses the multi-group structural equation modeling to pool correlation coefficients.

The three approaches of meta-analytic SEM include fixed-effect model, random-effect model, and mixed-effect model (Cheung, 2015).

In fixed-effect SEM, the effect sizes (correlations, covariance, path coefficients etc.) are assumed to be comprehensive summaries of many effect sizes and their estimated sampling variance (differences between studies are the result of sampling error only). If effect sizes are homogeneous across studies, the weighted average of effects is the unbiased estimate of the population effect size that share the common value.

The random-effect SEM assumes that studies are not simple replication of each other and the effect size may vary due to differences in samples and methods used in different studies. The random-effect SEM can be used where the researchers wish to make inferences and generalizations on the studies used in the analysis. Randomeffect SEM models include not only sampling variance, but also the between- studies variance components.

The mixed-effect model is used with covariate and it includes both fixed and random effects. The fixed effects are due to the study-specific covariates, and the random effects are the unexplained study-specific effects after being controlled for the covariates.

\section{RESULTS}

This paper integrated the 27 studies that used TAM models with Meta-analytic SEM, which was proposed by Davis, Bagozzi, and Warshaw (1989). The estimations were calculated using R 3.5.3 with the algorithm in Cheung's study (2014). This present paper only integrated the 1st generation TAM (Davis, Bagozzi, and Warshaw, 1989), which includes perceived ease of use (PEOU), perceived usefulness (PU), attitude towards use (ATT), and behavioral intention of use (BI).

Given the correlations, two-stage SEM was applied in obtaining pooled correlation matrix for subsequent TAM model. Both fixed-effect and random-effect models were estimated. In the fixed-effect model, the pooled correlation coefficients were calculated as unbiased estimates of population correlation matrix.

The result of fixed-effect model is as Table 2. Table 2 shows the estimates of correlation coefficients, their standard errors, $Z$ values and p-levels. There were 819 respondents in 27 studies. The estimate of PU to PEOU is 0.585 ( $\mathrm{z}$-value $=25.459$; $\mathrm{p}$-value $<0.001)$. The estimate of PU to ATT is 0.693 ( $\mathrm{z}$-value $=38.005 ; \mathrm{p}$-value $<0.001)$. The estimate of PU to BI is 0.573 ( $\mathrm{z}$-value $=24.316$; $\mathrm{p}$-value $<0.001$ ). The estimate of PEOU to ATT is 0.663 ( $\mathrm{z}$ value $=33.843 ; \mathrm{p}$-value $<0.001$ ). The estimate of PEOU to $\mathrm{BI}$ is 0.549 ( $\mathrm{z}$-value $=22.454 ; \mathrm{p}$-value $<0.001)$. The estimate of ATT to BI is 0.663 ( $\mathrm{z}$-value $=33.846$; $\mathrm{p}$-value $<0.001$ ). 
Pedagogical Research, 4(3), em0038

Table 3. Estimated pooled correlation coefficients (random-effect parameters)

\begin{tabular}{cccc}
\hline & Estimate & S.E. & Wald CI* \\
\hline Intercept of PU-PEOU & 0.6034 & 0.0243 & $(0.5557,0.6511)$ \\
\hline Intercept of PU-ATT & 0.7155 & 0.0248 & $(0.6668,0.7643)$ \\
\hline Intercept of PU-BI & 0.5972 & 0.0446 & $(0.5098,0.6847)$ \\
\hline Intercept of PEOU-ATT & 0.6724 & 0.0235 & $(0.6263,0.7185)$ \\
\hline Intercept of PEOU-BI & 0.5674 & 0.0367 & $(0.4953,0.6395)$ \\
\hline Intercept of ATT-BI & 0.6801 & 0.0205 & $(0.6399,0.7204)$ \\
\hline Tau of PU-PEOU & 0.0002 & 0.0012 & $(-0.0023,0.0027)$ \\
\hline Tau of PU-ATT & 0.0011 & 0.0016 & $(-0.0020,0.0043)$ \\
\hline Tau of PU-BI & 0.0057 & 0.0055 & $(-0.0019,0.0166)$ \\
\hline Tau of PEOU-ATT & 0.0003 & 0.0011 & $(-0.0051,0.0109)$ \\
\hline Tau of PEOU-BI & 0.0029 & 0.0040 & $(-0.0025,0.0025)$ \\
\hline Tau of ATT-BI & $<0.0001$ & 0.0012 &
\end{tabular}

Table 4. Q tests of effect size homogeneity $\left(\mathrm{I}^{2}\right)$

\begin{tabular}{cc}
\hline & Estimate \\
\hline Intercept of PU-PEOU & 0.0875 \\
\hline Intercept of PU-ATT & 0.4727 \\
\hline Intercept of PU-BI & 0.7258 \\
\hline Intercept of PEOU-ATT & 0.1691 \\
\hline Intercept of PEOU-BI & 0.5389 \\
\hline Intercept of ATT-BI & 0.0000 \\
\hline
\end{tabular}

The fit indices for testing the homogeneity of the correlation matrices in Table 2 are $X^{2}(\mathrm{df}=18 ; \mathrm{N}=819)$ $=56.3759 ; \mathrm{p}<0.0001, \mathrm{CFI}=0.9762, \mathrm{TLI}=0.9683, \mathrm{SRMR}=0.0518$, and RMSEA $=0.1021$. These values indicate that it is not reasonable to assume that the correlation matrices are homogeneous.

The result of random-effect model is as Table 3. In the random-effect model, the intercepts (effect sizes) and random effects (tau) were calculated. Table 3 presents the average (pooled) correlations (Intercept) and betweenstudy variances of correlation coefficients as random effects (Tau). Additionally, the random effect model provides the Q tests of effect sizes for the homogeneity across studies. The estimate of PU to PEOU is 0.6034 (Wald CI: $0.5557 \sim 0.6511$ ). The estimate of PU to ATT is 0.7155 (Wald CI: $0.6668 \sim 0.7643$ ). The estimate of PU to BI is 0.5972 (Wald CI: $0.5098 \sim 0.6847$ ). The estimate of PEOU to ATT is 0.6724 (Wald CI: $0.6263 \sim 0.7185$ ). The estimate of PEOU to BI is 0.5674 (Wald CI: $0.4953 \sim 0.6395$ ). The estimate of ATT to BI is 0.6801 (Wald CI: $0.6399 \sim 0.7204)$.

In Table 4, the Q statistic (58.94208; p-level<0.001) shows that the hypothesis concerning homogeneity of correlations across studies should be rejected. The heterogeneity indices based on $\mathrm{Q}$ statistic also provide the information about strong heterogeneity of correlation coefficients. The random-effects model is more appropriate than the fixed-effects model for this data set.

Because of correlation coefficients heterogeneity, the random-effect model was selected for the stage 2 solution. In stage 2, the TAM structural equation model based on pooled correlation matrix was estimated using $\mathrm{R} 3.5 .2$ and the path weight is calculated based on Cheung's study (Cheung, 2014).

The result of random-effects meta-analysis is in Table 5. The goodness of model fit is acceptable. The aggregate sample size is 819 . Chi-square of target model is 5.2133 with $\mathrm{df}=1$ and $\mathrm{p}$-value $=0.0224$. The RMSEA is marginally acceptable 0.0718 (CI: $0.0217 \sim 0.1373$ ) and comparative fit indices TLI and CFI are 0.9857 and 0.9976 respectively. The parameters of the TAM model depicted in Figure 2 were used as an a priori information for meta-analytic SEM model on primary data. 


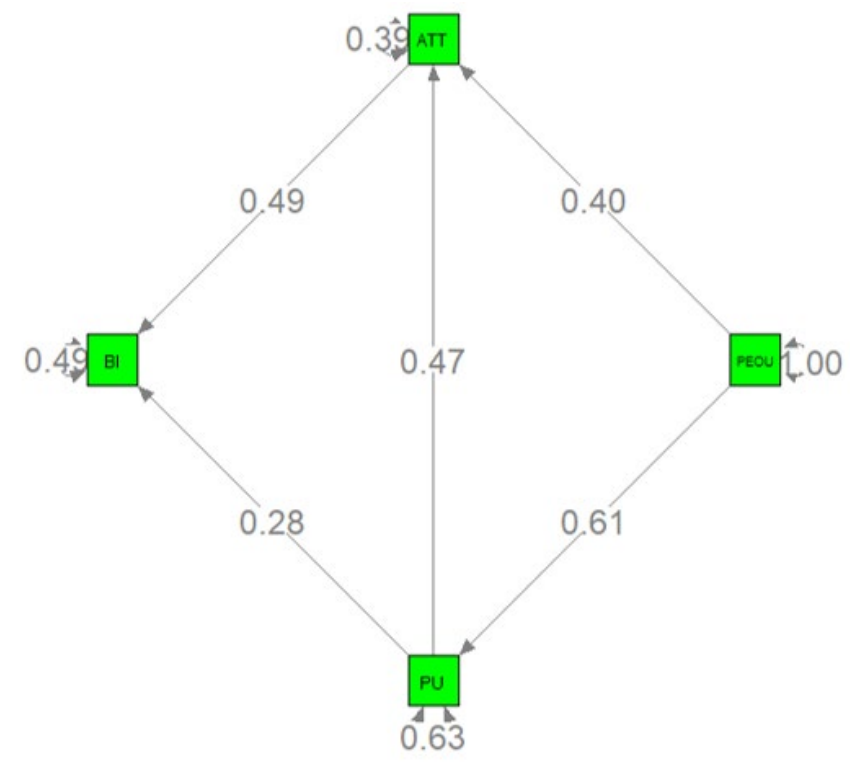

Figure 2. TAM path model estimates in this study

Table 5. Model parameters in tam model (random-effects meta-analysis)

\begin{tabular}{ccc}
\hline Paths and Residuals & Estimate & Wald CI* \\
\hline PEOU-> PU & 0.61226 & $(0.56487,0.65955)$ \\
\hline PU->ATT & 0.47104 & $(0.39147,0.54985)$ \\
\hline PEOU->ATT & 0.39502 & $(0.32151,0.46870)$ \\
\hline PU->BI & 0.27625 & $(0.35920,0.44333)$ \\
\hline ATT->BI & 0.49006 & $(0.56499,0.68093)$ \\
\hline Residual PU & 0.62514 & NA \\
\hline Residual PEOU & 1.00000 & $(0.33400,0.45158)$ \\
\hline Residual ATT & 0.39423 & $(0.41867,0.55157)$ \\
\hline Residual BI & 0.49050 &
\end{tabular}

*: 95\%Wald confidence interval (CI)

Table 6. The direct effects and indirect effects on attitude toward use and behavioral intentions to use

\begin{tabular}{cccc}
\hline & Estimate & CI* \\
\hline PEOU->BI & PEOU->PU->BI & 0.16914 & $(0.06267,0.27571)$ \\
\hline & PEOU->ATT->BI & 0.19358 & $(0.12977,0.26463)$ \\
\hline
\end{tabular}

*: $95 \%$ likelihood-based confidence interval

Table 7. The result of this study

\begin{tabular}{cccc}
\hline & Hypothesis & Fixed-effect Model & Random-effect Model \\
\hline H1 & PEOU-> PU & Support & Support \\
\hline H2 & PU->ATT & Support & Support \\
\hline H3 & PEOU->ATT & Support & Support \\
\hline H4 & PU->BI & Support & Support \\
\hline H5 & ATT->BI & Support & Support \\
\hline
\end{tabular}

Figure 2 and Table 5 show that the effects of PEOU on PU and ATT are 0.61226 and 0.39502 , the effects of PU on ATT and BI are 0.47104 and 0.27625 , and the effect of ATT on BI is 0.49006. All of these effects are statistically significant.

In Figure 1, PEOU and BI are mediators of the effect of PEOU on BI, and the indirect effects are via PU and ATT separately. The results demonstrate that the indirect effects via PU and ATT are 0.16914 and 0.19358 respectively. All of these effects are statistically significant (Table 6).

From the result of this study presented in Table 7, it has been found that first, perceived ease of use (PEOU) has a positive effect on perceived usefulness (PU) and attitude toward using interactive whiteboard (ATT) (H1 and H3). Second, perceived usefulness (PU) has a positive effect on attitude toward using interactive whiteboard (AT'T) and behavioral intentions to use interactive whiteboard (BI) (H2 and H4). Third, attitude toward using e interactive whiteboard (ATT) has a positive effect on and behavioral intentions to use interactive whiteboard (BI) (H5). 


\section{CONCLUSIONS}

Past studies on the use of new information technology focused on system development and behavioral intention to use it. However, with rapid development and popularity of information systems, discussion on the interactive whiteboard should not be centered merely on technological perspectives, since technologies continuously evolve and will reach maturity in the end. Many previous studies (Wong, Teo, and Russo, 2013) discussed the factors that affect teachers' behaviors in using interactive whiteboard with the TAM model proposed by Davis, Bagozzi, and Warshaw (1989), and they indicate that perceived usefulness and perceived ease of use play an import role in teachers' behaviors in using interactive whiteboard. But some studies (Kung, 2010; Ou, 2010) declare that teachers' behaviors in using interactive whiteboard only be infected by perceived usefulness, for teachers are a relatively small profession.

The objective of this research is to find out factors affecting teachers to use Interactive Whiteboards in classes with Meta-Analytic SEM. The integration of meta-analysis and SEM models provides a powerful tool for a model generation and parameter check. From the result of the integration of these 6 studies, it can be found that TAM model is a suitable model in discussing factors that affect teachers' behaviors in using interactive whiteboard. Perceived usefulness and perceived ease of use improve teachers' behaviors in using interactive whiteboard significant. Some studies (Kung, 2010; Ou, 2010) that are inconsistent with Davis, Bagozzi, and Warshaw's TAM model (Davis, Bagozzi, and Warshaw, 1989) may result in insufficient sample size or data bias.

Adult learning theory revealed that linking adult learners' previous experiences can stimulate to their reflective thinking when they are learning. What is more, when adult learners understand the technological tool can help solving their problems that can increase their learning motivation (Lowe and Holton, 2005).

It is important to develop a school culture and establish teaching counseling group, that would help teachers to shape the perception that would like them to use technology (Yuen, Ma, 2008). School directors should periodically hold the teaching observations. Teaching observations provide an opportunity to benefit both teachers and observers. Those teachers have not applied interactive whiteboard in teachers can have different experience, thus induce his/her interests. It's also a good way to show functions of interactive whiteboard and how to use it in lecturers.

As Slay, Sieborger, and Hodgkinson-Williams (2008) argue, teachers' understanding and practices is necessary to make optimum use of the promising technology tool. Conferences of teaching and training workshops can help teacher to gain confidence and skills with the interactive whiteboard technology (Merriam and Caffarella, 2007). In order to widely promote interactive whiteboard to every basic level school, all teachers have to be familiar with this technology. Therefore, administration of education is suggested to hold exhibitions, teaching observations and references for teachers of elementary and junior schools. If teachers feel interactive whiteboard is usefulness and ease of use and become acquainted with it, they will have higher willing to apply interactive whiteboard in teaching.

This study targets only on the teachers who serve in Taiwan. Due to the digital divide between the Eastern and Western countries and the different cultures, the result of this research fits to those East countries with Chinese culture.

\section{REFERENCES}

Abdullah, F. and Ward, R. (2016). Developing a General Extended Technology Acceptance Model for E-Learning (GETAMEL) by analysing commonly used external factors. Computers in Human Behavior, 56, 238-256. https://doi.org/10.1016/j.chb.2015.11.036

Al-Emran, M., Mezhuyev, V. and Kamaludin, A. (2018). Technology Acceptance Model in M-learning context: A systematic review. Computers \& Education, 125, 389-412. https:// doi.org/10.1016/j.compedu.2018.06.008

Chen, L. B. (2011). A Study on the Factors Affecting Elementary School Teachers' Use of Whiteboard (M.S. thesis). Department of Information Management, National Changhua University of Education, Changhua County, Taiwan. https://hdl.handle.net/11296/g89yb8

Chen, L. S. (2013). A Study of Key Factors Associated with Behavioral Intention in Using Interactive Whiteboard by the Elementary School Teachers in Taipei (M.S. thesis). Department of History and Geography, University of Taipei, Taipei city, Taiwan. https://hdl.handle.net/11296/tnnmms

Cheung, M. W. L. (2014). Fixed- and random-effects meta-analytic structural equation modeling: Examples and analyses in R. Behavior Research Methods, 46(1), 29-40. https://doi.org/10.3758/s13428-013-0361-y

Cheung, M. W. L. (2015). Meta-Analysis, A structural equation modeling approach. Hoboken, NJ, USA: John Wiley \& Sons, Inc. https:// doi.org/10.1080/10705511.2014.938713

Chiang, T. Y. (2017). Preschool Teacher's Acceptance of Interactive Whiteboards (IWB): A Study Based on the Technology Acceptance Model (M.S. thesis). Department of Computer Science \& Information Engineering, Asia University. Taichung city, Taiwan. https:// hdl.handle.net/11296/qs96kf 
Chou, P. Y. (2015). The Intention of Elementary School Teachers of Integrating Information Technology into Teaching through Extended Technology Acceptance Model-A Case Study of Interactive White Board (M.S. thesis). Department of information Management, Da-Yeh University, Changhua County, Taiwan. https://hdl.handle.net/11296/k79s92

Chu, W. T. (2012). A Study of elementary school teachers' in using Interactive Whiteboard teaching from the aspect of Technology Acceptance Model (TAM) for the expectations benefits (M.S. thesis). Department of Business Administration, KaoYuan University, Kaohsiung city, Taiwan. https://hdl.handle.net/11296/6n5zgp

Davis, F. D., Bagozzi, R. P. and Warshaw, P. R. (1989). User acceptance of computer technology: comparison of two theoretical models. Management Science, 35(8), 982-1003. https://doi.org/10.1287/mnsc.35.8.982

DiGregorio, P. and Sobel-Lojeski, K. (2010). The Effects of Interactive Whiteboards (IWBs) on Student Performance and Learning: A Literature Review. Journal of Educational Technology Systems, 38(3), $255-312$. https://doi.org/10.2190/ET.38.3.b

Gashan, A. K. and Alshumaimeri, Y. A. (2015). Teachers' attitudes toward using interactive whiteboards in English language classrooms. International Education Studies, 8(12), 176-184. https://doi.org/10.5539/ies.v8n12p176

Glass, G. V. (1976). Primary, secondary, and meta-analysis of research. Educational Researcher, 5(10), 3-8. https://doi.org/10.3102/0013189X005010003

Holmes, K. (2009). Planning to teach with digital tools: Introducing the interactive whiteboard to pre-service secondary mathematics teachers. Australasian Journal of Educational Technology, 25(3), $351-365$. https://doi.org/10.14742/ajet.1139

Hsiao, J. H. (2013). Using Technology Acceptance Model to Explore the Adoption of Interactive Whiteboard of Elementary Schools Teachers in National Taipei University of Education Experimental Elementary School (M.S. thesis). Department of Computer Science, National Taipei University of Education, Taipei city, Taiwan, 2013. https://hdl.handle.net/11296/6xz595

Hsieh, C. H. (2015). A Study of Kindergarten Teachers' Acceptance of the Use of Interactive Whiteboards (M.S. thesis). Department of Information Management, Cheng-Shiu University, Kaohsiung city, Taiwan. https://hdl.handle.net/11296/nyh9st

Hsu, S. (2010). Developing a scale for teacher integration of information and communication technology in grades 1-9. Journal of Computer Assisted Learning, 26(3), 175-189. https:/ / doi.org/10.1111/j.1365-2729.2010.00348.x

Hsueh, C. P. (2013). Applying the Technology Acceptance Model to Explore the Elementary School Teachers' Present Situation and Usage Intentions of Using Interactive Whiteboard in Tainan City (M.S. thesis). Department of Information and Learning Technology, National University of Tainan, Tainan city, Taiwan. https:/ / hdl.handle.net/11296/qs96kf

Huang, C. C. (2010). A Discussion of the Utilization for Interactive White Board in Information Technology Integrated Instruction by Junior High School Teachers (M.S. thesis). Department of Information and Communication, Shih-Hsin University, Taipei city, Taiwan. https://hdl.handle.net/11296/6zt5q2

Huang, K. S. (2012). A Survey of Teaching Situation of Elementary School Teachers on Using White Board in Pingtung County (M.S. thesis). Department of Education, National Taitung University, Taitung County, Taiwan. https://hdl.handle.net/11296/53b3nd

Jak, S. (2015). Meta-analytic structural equation modeling. Heidelberg, Berlin, Germany: Springer Science. https://doi.org/10.1007/978-3-319-27174-3

Kung, C. L. (2010). A Study of Adoption Intention of Using Interactive Whiteboard of Primary School Teachers in Kaohsiung County: Apply the Technology Acceptance (M.S. thesis). Department of Industrial Technology Education, National Kaohsiung Normal University, Kaohsiung city, Taiwan. https:/ / hdl.handle.net/11296/ qttv98

Kuo, M. H. (2017). Study on the Satisfaction of Kindergarten Teachers with Interactive Whiteboard Teaching (M.S. thesis). ShihHsin University, Department of information Management. Taipei city, Taiwan. https://hdl.handle.net/11296/gu3vc4

Lee, S. Y. (2011). The Behavioral Intention of Elemetery Teachers Using Interactive White Board Study (M.S. thesis). Department of Information Management, Shu-Te University, Kaohsiung city, Taiwan. https://hdl.handle.net/11296/c5rcrx

Li, H. C. (2012). The Investigation of Elementary School Teachers' Intentionsand Present Situation of Using Interactive Whiteboard in Tainan City (M.S. thesis). Department of Education, National University of Tainan, Tainan city, Taiwan. https://hdl.handle.net/11296/v5zx42

Lin, C. C. (2012). The Study on Using the Technology Acceptance Model for the Behavioral Intention of Interactive Whiteboard by the Resource Classrooms of Elementary Schools in Changhua County (M.S. thesis). Department of Technology Management, Chu-Hua University, Hsinchu city, Taiwan. https://hdl.handle.net/11296/zgr289

Lin, C. H. (2011). The Critical Factors Affecting Elementary and Junior High School Teachers' Use of Interactive Whiteboard (M.S. thesis). Department of Business Administration, Asia University, Taichung city, Taiwan, 2011. https://hdl.handle.net/11296/6s4wet 
Lowe, J. and Holton, E. F. (2005). A theory of effective computer-based instruction for adults. Human Resource Development Review, 4(2), 159-188. https:/ / doi.org/10.1177/1534484305276301

Merriam, S. B., Caffarella, R. S. and Baumgartner, L. M. (2007). Learning in adulthood: A comprehensive guide. San Francisco, CA, USA: John Wiley \& Sons.

Olivares, D. D. and Castillo, R. R. (2018). ICT in the classroom: Primary education student teachers' perceptions of the interactive whiteboard during the teaching practicum. Education and Information Technologies, 23(6), 23092321. https://doi.org/10.1007/s10639-018-9716-4

Ou, W. C. (2010). To Explore the Adoption of Electronic White Board in Elementary Schools Using the Technology Acceptance Model (M.S. thesis). Department of information Management, Nanhua University, Chiayi County, Taiwan. https://hdl.handle.net/11296/v56pac

Peng, C. Y. (2011). The teacher's acceptance on an interactive White Board in a kindergarten course - the TAM perspective (M.S. thesis). Department of Business Administration, Southern Taiwan University, Tainan City, Taiwan. https://hdl.handle.net/11296/g77964

Ro, S. C. (2010). The Study of Using Technology Acceptance Model to Explore the Adoption of Interactive Whiteboard of Elementary Schools Teachers in Taoyuan County (M.S. thesis). Department of Education, National Hsinchu University of Education, Hsinchu County, Taiwan. https://hdl.handle.net/11296/zx54u3

Shen, C. C. (2011). A Study on The Value Cognitive Structure of Interactive Information Technology - Based on The Case of Interactive White Board (Ph.D. dissertation). Department of Information Management, National Yunlin University of Science and Technology, Yunlin County, Taiwan, 2011. https://hdl.handle.net/11296/4p4th9

Shin, B. Y. Shih, C. H., Li, C. C., Chen, T. H., Chen, Y. H. and Chen, C. Y. (2011). Elementary school student's acceptance of Lego NXT: The technology acceptance model, a preliminary investigation. International Journal of the Physical Sciences, 6(22), 5054-5063. Available at: http://www.academicjournals.org/app/webroot/article/ article1380626307_Shih\%20et\%20al.pdf

Singaravelu, D. S. (2017). Attitude of student teachers towards the use of interactive whiteboard. International Education and Research Journal, 3(5), 15-23. Available at: http://researchersorganization.com/download/oct2013-2.pdf \#page $=83$

Slay, H., Sieborger, I. and Hodgkinson-Williams, C. (2008). Interactive whiteboards: Real beauty or just “lipstick"? Computers \& Education, 51, 1321-1341. https:// doi.org/10.1016/j.compedu.2007.12.006

Sue, C. Y. (2012). Study on Technology Acceptance of Elementary School Teachers Using Interactive White Board (M.S. thesis). Department of Information Management, Shu-Te University, Kaohsiung city, Taiwan. https://hdl.handle.net/11296/9s665q

Šumaka, B. and Šorgoab, A. (2016). The acceptance and use of interactive whiteboards among teachers: Differences in UTAUT determinants between pre- and post-adopters. Computers in Human Behavior, 64, 602620. https://doi.org/10.1016/j.chb.2016.07.037

Taiwanese National Central Library (2010). System Introduction, Taiwan Theses and Dissertations Knowledge Value-Added System. Available at: http://www.ncl.edu.tw

Taylor, S. and Todd, T.A. (1995). Understanding information technology usage: A test of competing models. Information Systems Research, 6(2), 144-176. https://doi.org/10.1287/isre.6.2.144

Tosuntaşa, S. B., Karadağa, E. and Orhanb, S. (2015). The factors affecting acceptance and use of interactive whiteboard within the scope of FATIH project: A structural equation model based on the Unified Theory of acceptance and use of technology. Computers \& Education, 81, 169-178. https://doi.org/10.1016/j.compedu. 2014.10.009

Wang, C. C. (2010). An Investigation on User Behavior in an Interactive Whiteboard Technology Environment by Interactivity and Technology Acceptance Model (M.S. thesis). Department of Information Management, National Yunlin University of Science and Technology, Yunlin County, Taiwan. https://hdl.handle.net/11296/jputa2

Weng, C. Y. (2010). The Study of the Acceptance of the Incorporation of Interactive White Board as an Innovativeness and Technology Acceptance Mode by Elementary School Teachers in Yunlin County (M.S. thesis). Department of Information Management, National Yunlin University of Science and Technology, Yunlin County, Taiwan. https://hdl.handle.net/11296/33gdsf

Wong, K. T., Teo, T. and Russo, S. (2013). Interactive Whiteboard Acceptance: Applicability of the UTAUT Model to Student Teachers. The Asia-Pacific Education Researcher, 22(1), 1-10. https://doi.org/10.1007/s40299-0120001-9

Wu, M. R. (2014). The Study of Using the Technology Acceptance Model to Examine Elementary School Teachers' Integrating IWB into Teaching (M.S. thesis). Institute of Education, National Sun Yat-sen University, Kaohsiung city, Taiwan. https://hdl.handle.net/11296/84e9h6

Yang, F. Y. (2012). A Study on the IWB Teaching Attitude \&; Behavior by Elementary School Teachers-using the Technology Acceptance Model (M.S. thesis). Department of Finance, National Changhua University of Education, Changhua County, Taiwan. https://hdl.handle.net/11296/y4jyta 
You, J. R. (2013). A Study of Primary and Junior High School Teachers' Continued Use Intention of Interactive Whiteboard in Taitung and Huailan-based on Technology Acceptance Model and Expectation Confirmation Theory (M.S. thesis). Department of Information Management, National Taitung University, Taitung County, Taiwan, 2013. https://hdl.handle.net/11296/dhxgm2

Yuen, A. H. K. and Ma, W. W. K. (2008). Exploring teacher acceptance of e-learning technology. Asia-Pacific Journal of Teacher Education, 36(3), 229-243. https:// doi.org/10.1080/13598660802232779

Zeng, Y. H. (2014). The Investigation of Acceptance and Current Situation of Using Interactive Whiteboard in Tainan City Elementary School Special Education Teachers (M.S. thesis). Department of Education, National University of Tainan, Tainan city, Taiwan. https://hdl.handle.net/11296/ts553k

Zhang, Y. (2019). Investigating K-12 teachers' use of electronic board in the classroom in the Central South of United States. Education and Information Technologies, 24(1), 825-841. https://doi.org/10.1007/s10639-018-98009 